\title{
The complete plastomes of seven Peucedanum plants: comparative and phylogenetic analyses for the Peucedanum genus
}

\author{
Chang-Kun Liu, Jia-Qing Lei, Qiu-Ping Jiang, Song-Dong Zhou* and Xing-Jin He*
}

\begin{abstract}
Background: The Peucedanum genus is the backbone member of Apiaceae, with many economically and medically important plants. Although the previous studies on Peucedanum provide us with a good research basis, there are still unclear phylogenetic relationships and many taxonomic problems in Peucedanum, and a robust phylogenetic framework of this genus still has not been obtained, which severely hampers the improvement and revision of taxonomic system for this genus. The plastid genomes possessing more variable characters have potential for reconstructing a robust phylogeny in plants.
\end{abstract}

Results: In the current study, we newly sequenced and assembled seven Peucedanum plastid genomes. Together with five previously published plastid genomes of Peucedanum, we performed a comprehensively comparative analyses for this genus. Twelve Peucedanum plastomes were similar in terms of genome structure, codon bias, RNA editing sites, and SSRs, but varied in genome size, gene content and arrangement, and border of SC/IR. Fifteen mutation hotspot regions were identified among plastid genomes that can serve as candidate DNA barcodes for species identification in Peucedanum. Our phylogenetic analyses based on plastid genomes generated a phylogeny with high supports and resolutions for Peucedanum that robustly supported the non-monophyly of genus Peucedanum.

Conclusion: The plastid genomes of Peucedanum showed both conservation and diversity. The plastid genome data were efficient and powerful for improving the supports and resolutions of phylogeny for the complex Peucedanum genus. In summary, our study provides new sights into the plastid genome evolution, taxonomy, and phylogeny for Peucedanum species.

Keywords: Apiaceae, Peucedanum, Plastome evolution, Phylogenomics, DNA barcoding

\section{Background}

Peucedanum L. is one of the largest genera of Apiaceae [1-3], which was once placed in the tribe Peucedaneae $[1,4,5]$, but now in the tribe Selineae [2]. The genus comprises $100-120$ species worldwide that are widely

*Correspondence: zsd@scu.edu.cn; xjhe@scu.edu.cn

Key Laboratory of Bio-Resources and Eco-Environment of Ministry

of Education, College of Life Sciences, Sichuan University,

Chengdu 610065, China distributed in Eurasia and South Africa (and sometimes Australia) [2, 3, 6], with Europe and East Asia as distribution centers [7]. Of those, forty species are distributed in China with 33 of them endemic [3].

The genus Peucedanum is taxonomically notorious within Apiaceae family, especially described as "Peucedanum problem" by Downie et al. [8]. Its members are characterized by dorsally compressed mericarps with slightly prominent dorsal ribs, narrowly winged lateral ribs, as well as a broad commissure [2, 3]. However, the 
genus is extremely heterogenous and exhibits great diversity in life-forms, leaf and fruit structures, and chemical constituents [9]. Hence, several researchers are prone to divide this genus into smaller and presumably more natural units. For example, Pimenov and Leonov [5] suggested that all members of Peucedanum except 8-10 species included in sect. Peucedanum should be transferred to other genera. Based on morphological and phytochemical evidences, Reduron et al. [10] separated the genera Cervaria Wolf, Imperatoria L., Oreoselinum Mill., Pteroselinum Rchb., Thysselinum Adans., Xanthoselinum Schur and Holandrea Reduron from Peucedanum. Winter et al. [11] established three new genera (Afrosciadium P.J.D. Winter, Nanobubon Magee and Notobubon B.-E. van Wyk) to accommodate the African peucedanoid species and transferred 24 Peucedanum species into Afroligusticum C. Norman, Cynorhiza Eckl. \& Zeyh., and Lefebvrea A. Rich. However, due to the varied morphological features of leaf division, bracteoles, and mericarps, distinguishing separate genera from Peucedanum is extremely difficult $[2,3]$. Therefore, the generic limits of Peucedanum based on morphological characters faces challenges.

A robust phylogenetic framework could provide a valuable information to aid the generic delimitation of Peucedanum. Previously, a few molecular phylogenies of Peucedanum based on single or multiple-locus DNA sequence data, such as nuclear ribosomal DNA internal transcribed spacer (ITS), plastid DNA rpl16 and rps 16 intron, have been performed, yet these analyses failed to recognize Peucedanum as a monophyletic group [2, 12-16]. This phenomenon infers that re-evaluating the generic limits of Peucedanum may be essential. Nevertheless, weak supports and low resolutions of these phylogenetic trees could not provide sufficient information to support the improvement of taxonomy for Peucedanum. Therefore, additional molecular data are urgent to reconstruct a strong phylogeny.

In addition, several species of Peucedanum are highly appreciated as traditional medicinal herbs due to their versatile therapeutic properties [17]. Among them, Peucedanum praeruptorum Dunn, known as "Baihu Qianhu", is an excellent representation. The dried root of P. praeruptorum has been utilized as traditional Chinese medicine for more than 1500 years, which is generally used to treat respiratory diseases, pulmonary hypertension, chest pain, as well as symptomatic coughs and dyspnea [18]. However, most Peucedanum species exhibit abundant intraspecific variations in morphology that make it difficult to accurately identify species. In order to assure medicinal quality, it is, therefore, necessary to develop specific DNA marker for Peucedanum species authentication.
The plastid genome (plastome) is one of the three DNA genomes (with nuclear and mitochondrial genomes) in plants. The genome is uniparentally inherited, lacks recombination, and possesses highly variable characters in flowering plants; hence, it has the potential to significantly improve the supports and resolutions of the phylogeny [19-22]. Furthermore, a typical plastome comprises two inverted repeats regions (IRs) of 22-25 kb separated by the large single copy region (LSC) of $82-90$ $\mathrm{kb}$ and small single copy region (SSC) of $15-20 \mathrm{~kb}$ and generally encodes 110-130 unique genes [23, 24]. Comparative analysis of plastome could reveal the diversity of plastome in structural organization, gene arrangement and content that deepens our understanding of adaptive evolution for plant lineages and identify suitable mutation hotspots for species authentication [21, $25,26]$. Hence, with the development of next-generation sequencing and bioinformatics technologies, plastomes have been extensively and successfully used for plant phylogenetic analyses and development of specific DNA barcodes in recent years [25-32].

Currently, although six plastomes of Peucedanum species were submitted in GenBank [33-36], the plastid phylogenomic analysis of the genus has not been conducted. In this study, we newly sequenced the plastomes of seven Peucedanum taxa. In conjunction with the previously reported five plastomes of Peucedanum, we carried out a comprehensive analysis of plastomes for this taxonomically difficult plant group. Our aims were to: (1) investigate the plastome features of Peucedanum plants; (2) screen out suitable mutation hotspot regions from plastome as candidate DNA barcodes for species identification of Peucedanum; (3) test the power of plastome for improving the supports and resolutions of phylogeny in the complex Peucedanum genus. Overall, our results will well lay the foundation for the phylogenetic and taxonomic studies of Peucedanum.

\section{Results}

\section{Plastome features of Peucedanum}

Illumina sequencing generated 36,875,778-44,140,972 paired-end clean reads for the seven Peucedanum samples. Among them, 712,889 to $6,125,929$ reads were mapped to the final assembly. Based on these data, we obtained seven high-quality Peucedanum plastomes, with coverage ranging from $730.073 \times$ to $6,266.178 \times$ (Table S1).

Overall size of plastomes ranged from 142,494 bp (P. angelicoides Wolff ex Kretschm.) to 156,899 bp (P. insolens Kitag.) for the twelve Peucedanum samples (Table 1). All of them shown typically quadripartite structure, including a pair of inverted repeats regions (IRs, 12,594-27,495 bp), a large single copy region 
Table 1 Comparison of plastome features among Peucedaum plants

\begin{tabular}{|c|c|c|c|c|c|c|c|c|c|}
\hline Taxon & Total length (bp) & LSC (bp) & SSC (bp) & IR (bp) & $\begin{array}{l}\text { Total GC } \\
\text { content } \\
(\%)\end{array}$ & $\begin{array}{l}\text { Total } \\
\text { genes } \\
\text { (unique) }\end{array}$ & $\begin{array}{l}\text { Protein coding } \\
\text { genes (unique) }\end{array}$ & $\begin{array}{l}\text { rRNA } \\
\text { genes } \\
\text { (unique) }\end{array}$ & $\begin{array}{l}\text { tRNA } \\
\text { genes } \\
\text { (unique) }\end{array}$ \\
\hline P. ampliatum & 147,403 & 92,526 & 17,519 & 18,679 & 37.6 & 114 & 80 & 4 & 30 \\
\hline P. angelicoides & 142,494 & 99,934 & 17,372 & 12,594 & 37.4 & 114 & 80 & 4 & 30 \\
\hline P. chujaense & 147,839 & 93,335 & 17,590 & 18,457 & 37.4 & 114 & 80 & 4 & 30 \\
\hline P. delavayi & 155,552 & 85,276 & 17,394 & 26,441 & 37.6 & 113 & 79 & 4 & 30 \\
\hline P. harry-smithii var. grande & 147,046 & 92,135 & 17,627 & 18,642 & 37.6 & 113 & 80 & 4 & 29 \\
\hline P. insolens & 156,899 & 84,492 & 17,417 & 27,495 & 37.7 & 113 & 79 & 4 & 30 \\
\hline P.japonicum & 147,592 & 92,804 & 17,576 & 18,606 & 37.5 & 114 & 80 & 4 & 30 \\
\hline P.longshengense & 147,967 & 93,265 & 17,572 & 18,565 & 37.5 & 114 & 80 & 4 & 30 \\
\hline P. mashanense & 154,230 & 86,957 & 16,665 & 25,304 & 37.4 & 114 & 80 & 4 & 30 \\
\hline P. medicum & 152,288 & 86,645 & 17,571 & 24,036 & 37.5 & 114 & 80 & 4 & 30 \\
\hline P. praeruptorum & 147,197 & 92,161 & 17,610 & 18,713 & 37.6 & 113 & 80 & 4 & 29 \\
\hline P. terebinthaceum & 147,925 & 93,368 & 17,571 & 18,493 & 37.5 & 114 & 80 & 4 & 30 \\
\hline
\end{tabular}

(LSC, 84,492-99,934 bp), and a small single copy region (SSC, 16,665-17,627 bp) (Fig. 1, Table 1). The total GC content of the twelve plastomes ranged from $37.4 \%$ to 37.7\% (Table 1). The twelve plastomes encoded 113-114 unique genes, including 79-80 protein-coding genes, 29-30 tRNA genes, and four rRNA genes (Table 1, Table S2). The $y c f 15$ gene was lost in $P$. delavayi Franch. and $P$. insolens; the trnT-GGU gene was absent in $P$. praeruptorum and $P$. harry-smithii var. grande (K.T.Fu) Shan et Sheh (Table S2).

In order to analyze the codon usage of Peucedanum plastomes, 79 protein-coding genes were extracted and connected for each plastome. These sequences were $66,552-68,130 \mathrm{bp}$ in length and encoded 22,184-22,710 codons. The Leu was encoded by the highest number of codons $(2,347-2,404)$, while the Cys was the least (234243) in all plastomes (Table S3). In addition, relative synonymous codon usage (RSCU) values of all codons ranged from 0.32 to 2.01 in the twelve plastomes (Table S3). Specifically, RSCU values of 30 codons were greater than 1.00 in all plastomes, whereas the codon AUA with RSCU > 1.00 was only detected in P. insolens plastomes (Fig. 2). All codons with RSCU > 1.00 were ended with A/U, except UUG (Fig. 2).

The potential RNA editing sites for 35 protein-coding genes of the twelve plastomes were detected. A total of 56-60 potential RNA editing sites were identified (Table S4, Fig. S1). All detected RNA editing sites were Cytosine to Uracil (C-U) conversion and most of them occurred in the second codon position (42-45), followed by the first codon position (12-16), but no sites situated in the third codon position (Fig. S1A). Moreover, the $n d h \mathrm{~B}$ gene contained the highest number of RNA editing sites ranging from 10 to 11 (Fig. S1B).
The total number of SSRs ranged from 58 to 89 among the twelve Peucedanum plastomes (Fig. 3, Table S5). Most of the SSRs distributed in the LSC region for all plastomes (Fig. 3A). Among these SSRs, the mononucleotide repeats were the most abundant (28-54), followed by the dinucleotides (14-21) (Fig. 3B). In addition, bases $\mathrm{A}$ and $\mathrm{T}$ were the dominant elements for all identified SSRs in the twelve plastomes.

\section{Plastome comparison and hotspots identification}

The borders of IRa/SSC, IRb/SSC, and IRb/LSC among the twelve Peucedanum plastomes were slightly conserved: the IRa/SSC junctions of most samples were located between $y c f 1$ gene and $n d h \mathrm{~F}$ gene, but expanded into $n d h \mathrm{~F}$ gene in $P$. delavayi and $P$. angelicoides; the boundaries of IRb/SSC fell into $y c f 1$ gene; the IRb/LSC borders of most samples were located between genes of $t r n \mathrm{~L}$ and $t r n \mathrm{H}$, but extremely expanded into $p s b \mathrm{~A}$ gene in P. angelicoides (Fig. 4). However, the junctions of IRa/LSC of plastomes within Peucedanum genus were divergent and could be classified into four different types. The junctions of IRa/LSC fell into the rps 19 gene in $P$. delavayi and $P$. insolens, belonging to the type I; the IRa/LSC borders contracted to the intergenic region of $\operatorname{trn} \mathrm{L}-\operatorname{trn} \mathrm{H}$ in $P$. angelicoides (type II) while moved to the intergenic regions of rpl2-trnI in P. mashanense Shan et Sheh and P. medicum Dunn (type III); the IRa/LSC borders of most remainder Peucedanum plants fell into the $y c f 2$ gene, but contracted to the intergenic regions of $y c f 2-\operatorname{trn} \mathrm{L}$ in $P$. chujaense K. Kim, S.H. Oh, C.S. Kim \& C.W. Park and $P$. terebinthaceum (Fisch.) Fisch. ex Turcz. (type IV) (Fig. 4).

The genes arrangement of the twelve Peucedanum plastomes was relatively conserved, except for an inversion of the trnY-trnD-trnE gene detected in P. japonicum 


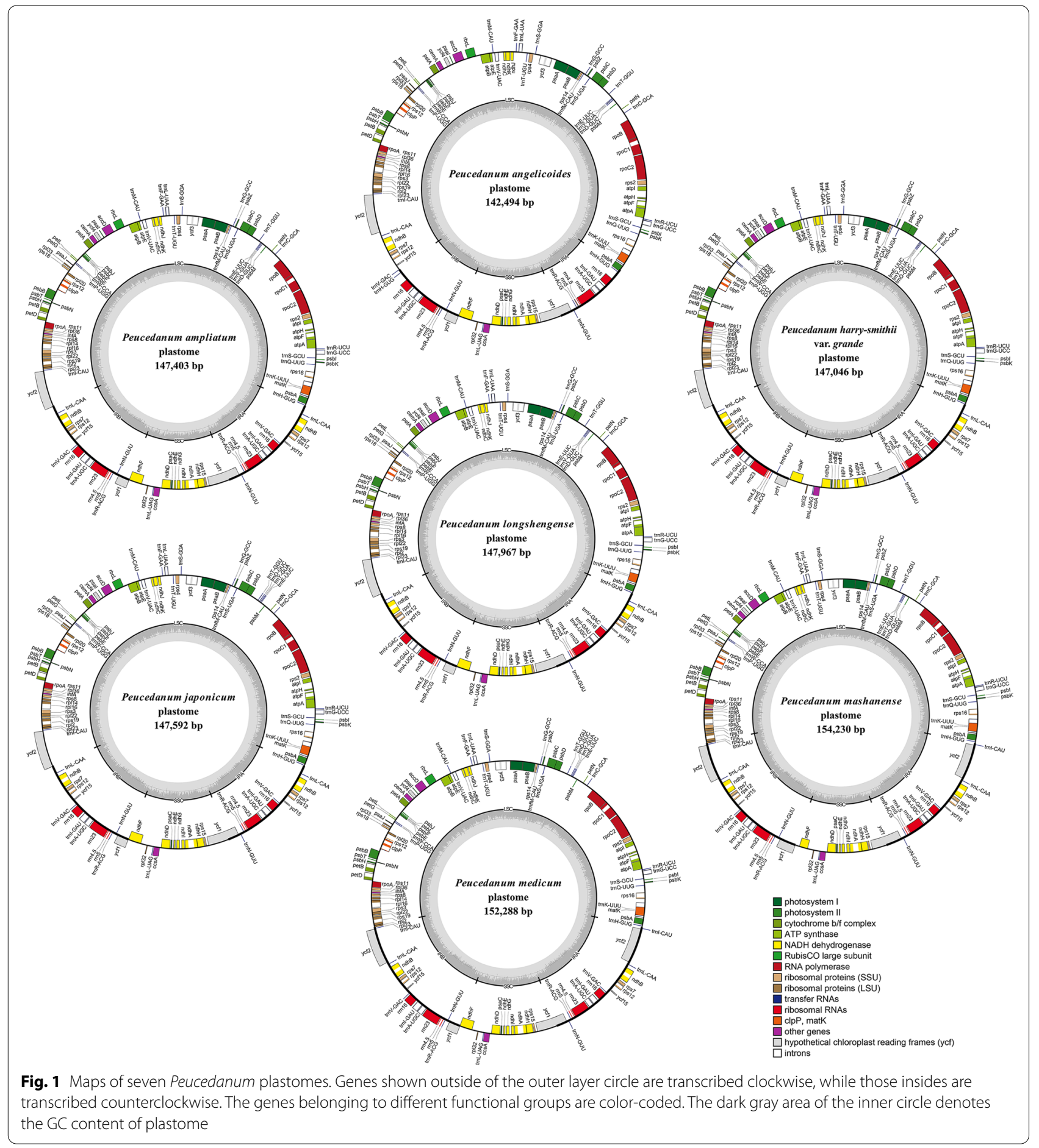

Thunb. and P. medicum (Fig. 5). However, the whole plastome sequences shared low similarity among the twelve Peucedanum samples, identifying 7,350 variation sites in the 142,197 alignment positions (Fig. 6). According to the sequence divergences, the 15 mutation hotspot regions were selected as candidate DNA barcodes, including five protein coding genes-ccsA, matK, rpl22, rps8, $y c f 1$-which showed the $\mathrm{Pi}>0.01200$ (Fig. 7A) and 10 non-coding regions-ccsA- $n d h \mathrm{D}, n d h \mathrm{~F}-r p l 32$, pet $\mathrm{A}-$ $p s b \mathrm{~J}, \quad p s b \mathrm{~A}-t r n \mathrm{~K}, \quad r p l 32-t r n \mathrm{~L}, \quad r p s 15-y c f 1$, rps2-rpoC2, $\operatorname{trn\mathrm {H}}-p s b \mathrm{~A}, \operatorname{trn\mathrm {K}}-r p s 16, y c f 2-\operatorname{tr} n \mathrm{~L}-$ which showed the $\mathrm{Pi}$ $>0.03100$ (Fig. 7B). 


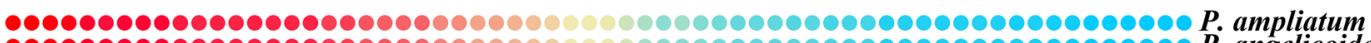

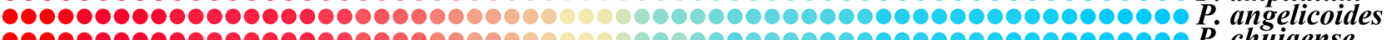

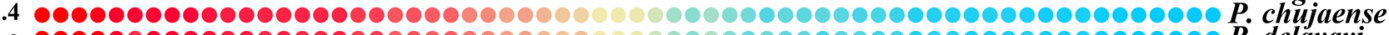

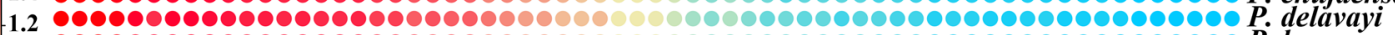


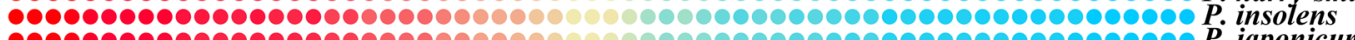
0.8 00000000000000000000000000000000000000000000000000000000000000 P. japonicum 0.6 4 0000000000000000000000000000000000000000000000000000000000000000 P. mashanense  0000000000000000000000000000000000000000000000000000000000000 P. terebinthaceum S

Fig. 2 The RSCU values of all concatenated protein-coding genes for 12 Peucedanum plastomes. Color key: the red values represent higher RSCU values while the blue values indicate lower RSCU values
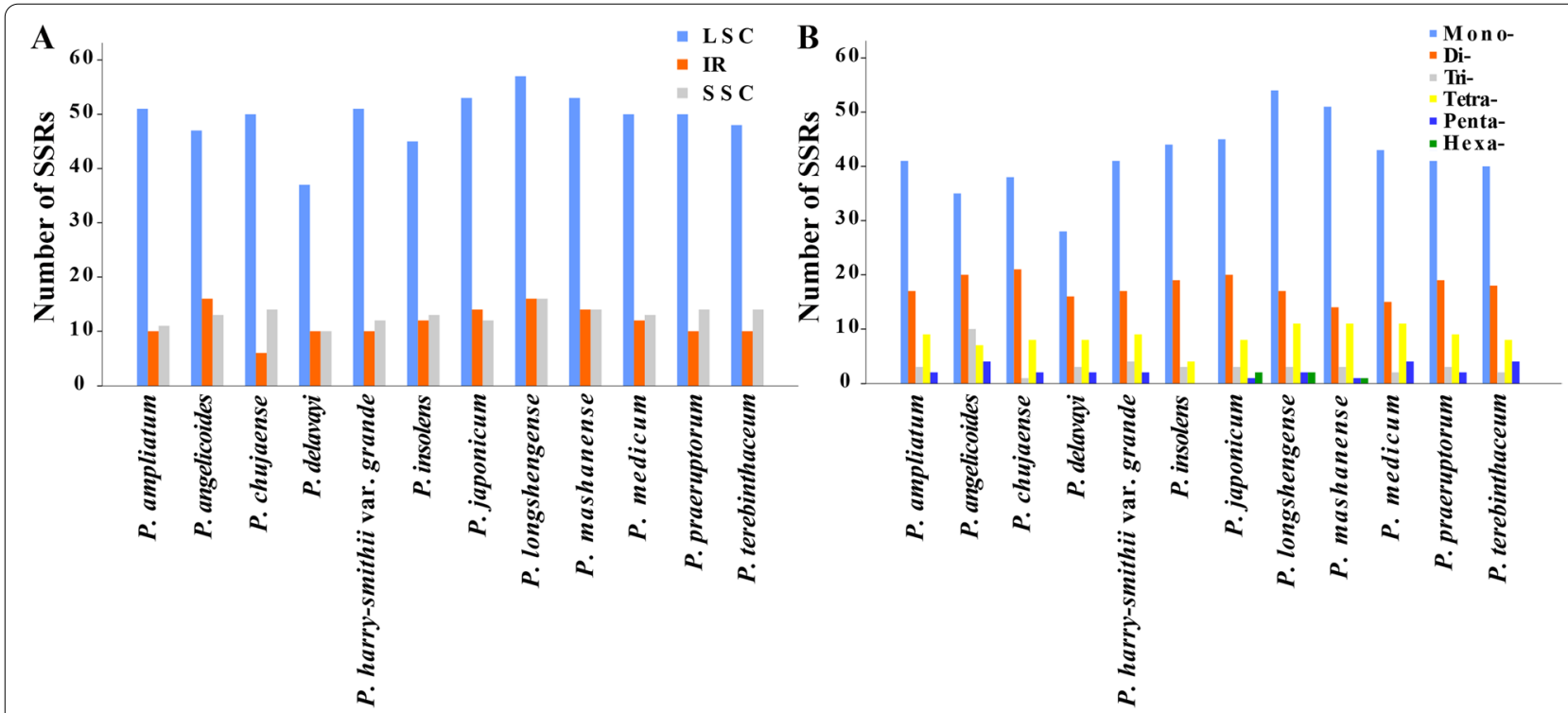

Fig. 3 Analyses of simple sequence repeats (SSRs) in twelve Peucedanum plastomes: A presence of SSRs in LSC, SSC, and IR; B numbers of different repeat types

\section{Phylogenetic analyses}

The analyses of ML and BI generated the identical tree topology. The Fig. 8 illustrated the phylogeny, including two types of support values: BI posterior probabilities (PP) and ML bootstrap values (BS). Both analyses robustly supported that members of Peucedanum not clustered as monophyletic but fell into four clades: (1) $P$. insolens was placed in Arcuatopterus clade $(\mathrm{PP}=1.00$, $\mathrm{BS}=100)$; (2) P. delavayi was sister to Pterygopleurum neurophyllum (Maxim.) Kitag., belonging to Acronema clade ( $\mathrm{PP}=1.00, \mathrm{BS}=100)$; (3) P. angelicoides clustered with Semenovia transiliensis Regel \& Herder constituting Tordyliinae ( $\mathrm{PP}=1.00, \mathrm{BS}=100)$; (4) the remainders were included in Selineae $(\mathrm{PP}=1.00, \mathrm{BS}=$ 100). Most of the Peucedanum accessions fell into the tribe Selineae, while these samples were also not clustered in a clade. Within Selineae, three major lineages for Peucedanum accessions were recognized: $P$. chujaense and $P$. terebinthaceum formed a clade that was relatively distant from others $(\mathrm{PP}=1.00, \mathrm{BS}=100)$; P. mashanense was clustered with $P$. medicum ( $\mathrm{PP}=$ 1.00 , BS $=100)$; P. ampliatum K.T. Fu, P. praeruptorum, $P$. harry-smithii var. grande, $P$. japonicum, and $P$. longshengense Shan et Sheh formed a clade $(\mathrm{PP}=1.00$, BS $=100)$, in which $P$. longshengense firstly diverged from the remainders $(\mathrm{PP}=1.00, \mathrm{BS}=100)$, followed by $P$. japonicum $(\mathrm{PP}=1.00, \mathrm{BS}=99)$, and the sub-clade $P$. praeruptorum $+P$. harry-smithii var. grande sister to P. ampliatum $(\mathrm{PP}=1.00, \mathrm{BS}=100)$. In addition, the phylogenetic relationships among non-Peucedanum species inferred in this study were generally consistent with the previous work [37], but our results gave the higher support values for these relationships, showing $\mathrm{PP}=1.00$ and $\mathrm{BS} \geq 96$ for all nodes. 


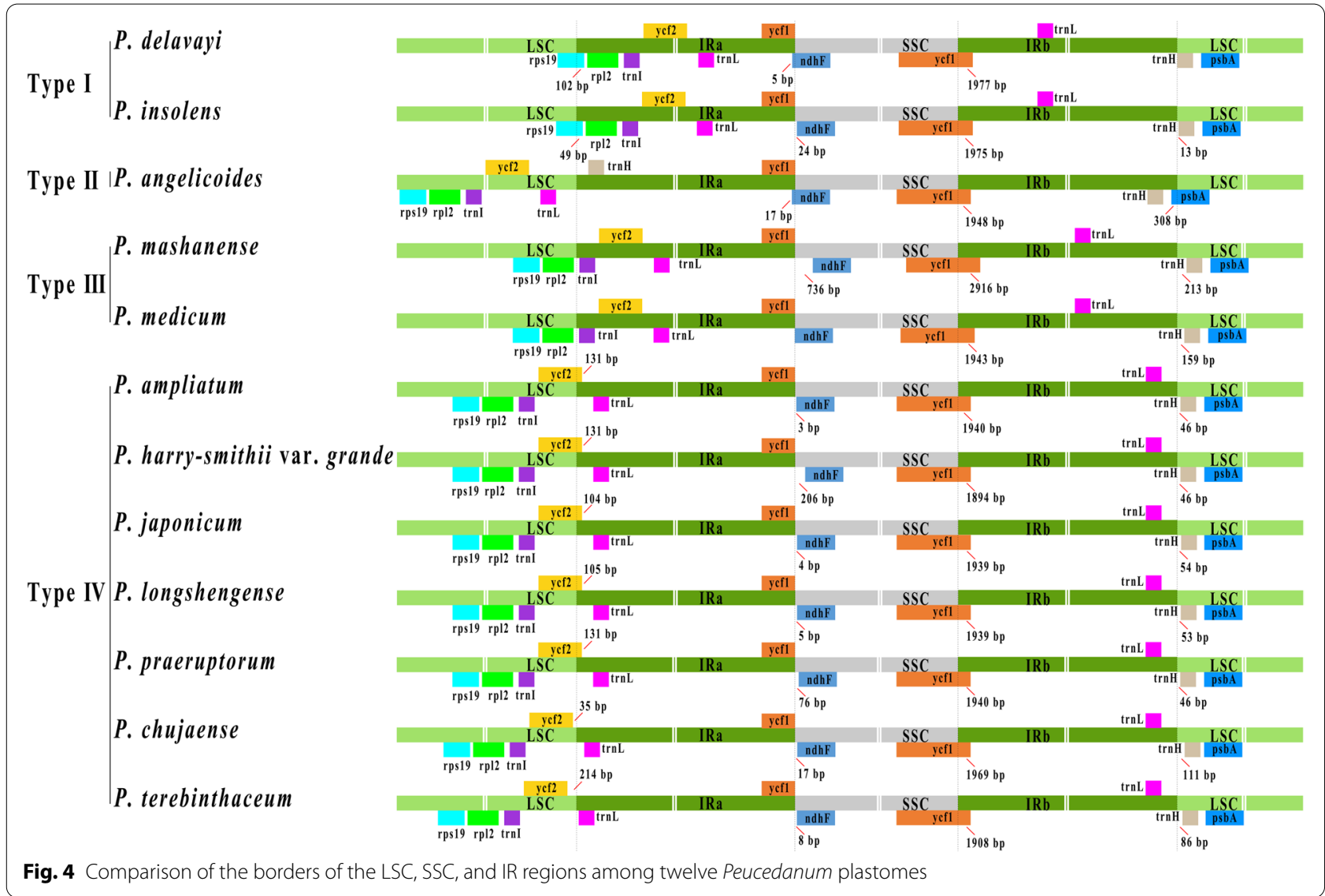

\section{Discussion}

\section{Comparison of the plastomes in Peucedanum}

In this study, we sequenced and assembled seven plastomes of Peucedanum and performed a comprehensive comparative analyses of these plastomes with five other published plastomes of this genus obtained from GenBank. All Peucedanum plastomes showed a typically quadripartite structure, including a pair of inverted repeats regions separated by the large single copy region and small single copy region [33-36]. In addition, codon bias, RNA editing sites, and the distribution and constituent of SSRs were quite similar among twelve Peucedanum plastomes. These results suggested that Peucedanum plastome is conserved in terms of genome structure, codon bias, RNA editing sites, and SSRs. It is worth noting that this phenomenon is commonly found in other genera of flowering plants [38-40], which may be related to maintaining the stability of plastome function.

However, we also detected obvious diversity among the twelve Peucedanum plastomes. First, the overall sizes of plastomes varied from 142,494 bp (P. angelicoides) to $156,899 \mathrm{bp}$ (P. insolens) among Peucedanum plants. Second, the $y c f 15$ gene was lost in P. delavayi and $P$. insolens, whereas the trnT-GGU gene was absent in $P$. praeruptorum and $P$. harry-smithii var. grande. The loss of the $y c f 15$ gene has been detected in a wide diversity of lineages in the angiosperms [41-44], which may occur independently during the evolution of these lineages, hence, it may not provide relevant phylogenetic information. However, the loss of trnT-GGU gene was only observed in P. praeruptorum and $P$. harry-smithii var. grande and not identified in other members of Apiaceae [26, 37, 39], and thus it can be used as specific molecular marker to recognize this group. Third, the inversion of the trnY-trnD-trnE gene was detected in P. japonicum and P. medicum, which has been observed in Angelica L. species [26]. Finally, we observed extensive expansion and contraction of the IR regions among Peucedanum samples, recognizing four types of SC/IR border. All patterns have been observed in other genera of Apiaceae [26, 37, 39]. Overall, these plastome divergences detected among Peucedanum members further implied the non-monophyly of the Peucedanum genus. 


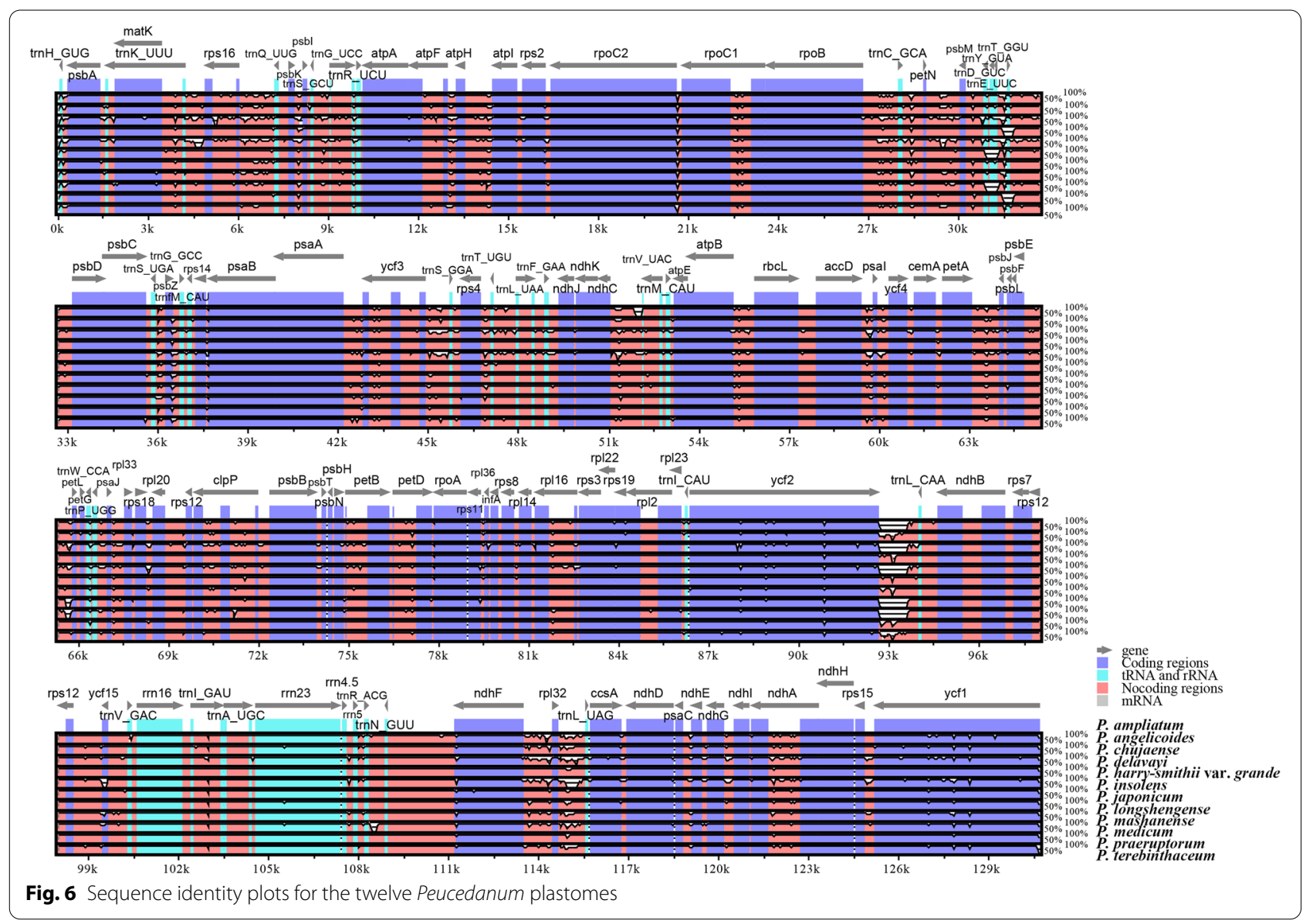

The Peucedanum genus was not recovered as monophyletic in our phylogenomic analyses, which was congruent with the previous studies that used ITS data and two plastid DNA regions (rpl16 and rps16 intron) [2, 12-16]. It is further supported by the great divergence of leaf epidermal morphologies [48], and fruit structures $[49,50]$ among Peucedanum members. These results justified that the Peucedanum genus is not a natural taxonomy unit. Therefore, the current taxonomy system of Peucedanum urgently needs to be improved and revised. Although the taxonomic treatment for Peucedanum members has not been performed in the current study due to the absence of the type species of Peucedanum (P. officinale L.), our results lay the foundations for the future taxonomic studies of Peucedanum.

The phylogenetic relationships among P. japonicum, $P$. praeruptorum, and $P$. terebinthaceum have long been controversial $[14,51,52]$. The phylogenetic analyses of Feng et al. [14] based on ITS sequences showed that $P$. praeruptorum was sister to $P$. japonicum that was relatively distant from $P$. terebinthaceum. However, the results of Ostroumova et al. [51] and Pimenov et al. [52] indicated that $P$. praeruptorum made a cluster with $P$. terebinthaceum being sister to P. japonicum. Our plastid phylogenomic analyses robustly supported that $P$. japonicum was sister to the clade consisting of $P$. ampliatum, $P$. praeruptorum and $P$. harry-smithii var. grande, in which the subclade of $P$. praeruptorum $+P$. harry-smithii var. grande diverged from $P$. ampliatum; $P$. terebinthaceum and $P$. chujaense clustered into a clade that was distant from all other Peucedanum members. The relationships recovered in the current study are different from those of previous studies [14, 51, 52]. With high supports and resolutions, our plastid-based phylogenetic analyses provide new sights into the inter-species relationship within Peucedanum.

\section{Potential DNA barcodes}

The accurate species identification has always been a serious challenge faced by taxonomists. The advent of DNA barcoding technology, which uses the short DNA sequences with sufficient variations to discriminate species [53], promises to resolve this difficulty. The mitochondrial gene cytochrome oxidase 1 has been proven to be effective and reliable as a standard DNA barcode for animal species identification [54-57]. However, in plants, 


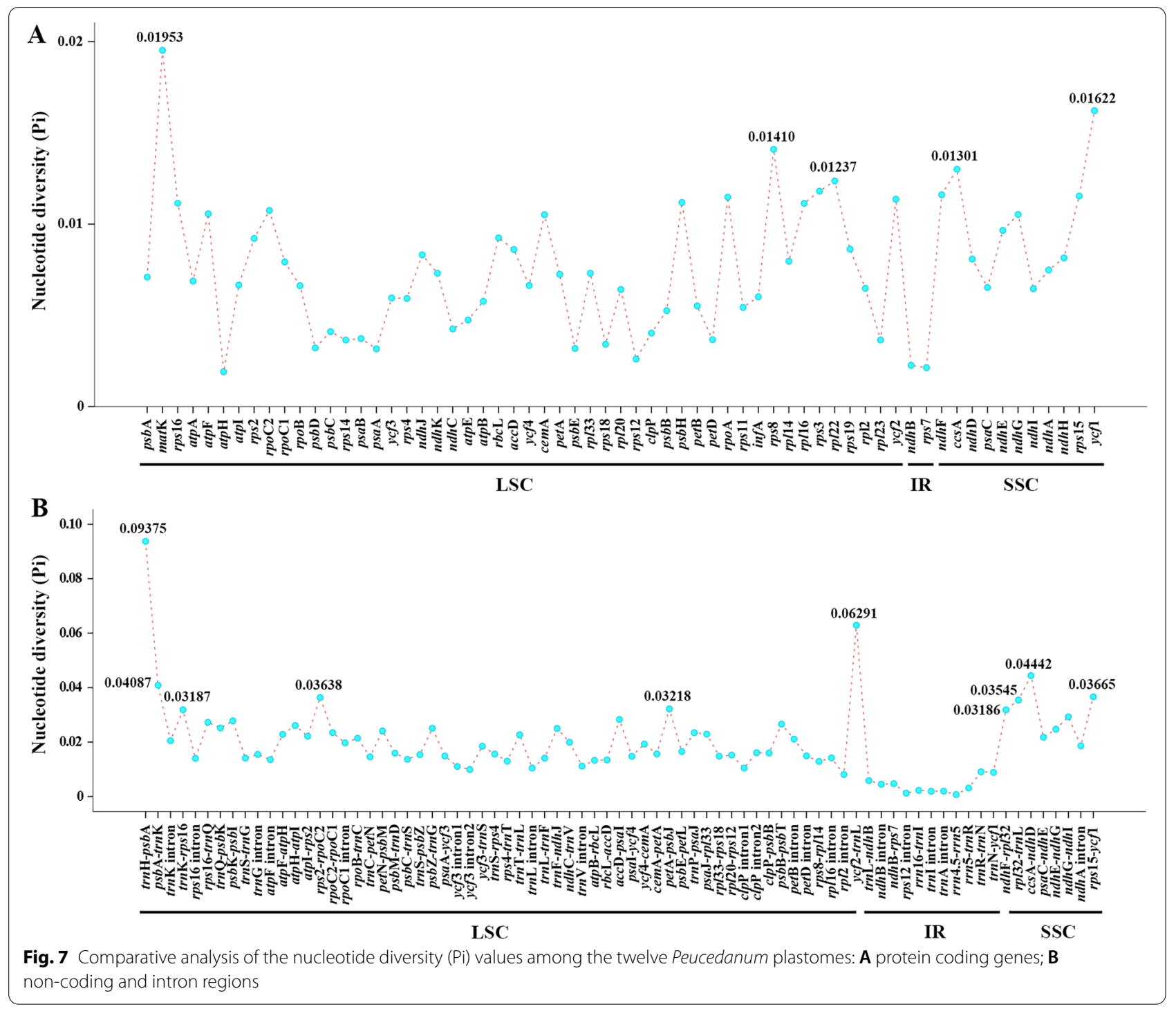

reliable species identification based on universal DNA barcodes, i.e., $r b c \mathrm{~L}, m a t \mathrm{~K}, t r n \mathrm{H}-p s b \mathrm{~A}$, is frequently problematic [58-62]. As expected, we found that the variation in $r b c \mathrm{~L}$ gene was relatively low $(\mathrm{Pi}=0.00925)$ among Peucedanum plants. Hence, this region may have limited power to discriminate Peucedanum species.

Based on sequence variations, five protein coding genes (ccs $\mathrm{A}$, mat $\mathrm{K}, r p l 22, r p s 8, y c f 1)$ and ten non-coding regions (ccsA-ndhD, $n d h \mathrm{~F}-r p l 32$, petA-psb), psbA-trnK, $r p l 32-t r n \mathrm{~L}, \quad r p s 15-y c f 1, \quad r p s 2-r p o C 2, \operatorname{trn} \mathrm{H}-p s b \mathrm{~A}, \operatorname{trnK}-$ $r p s 16, y c f 2$-trnL) were selected, which were potentially useful for species identification in Peucedanum genus. Among them, mat $\mathrm{K}$ gene and $t r n \mathrm{H}-p s b \mathrm{~A}$ region are members of universal DNA barcodes [62]; ccsA, rpl22, $y c f 1, c c s \mathrm{~A}-n d h \mathrm{D}, n d h \mathrm{~F}-r p l 32$, trnK-rps 16 , and $y c f 2-\operatorname{trn} \mathrm{L}$ have been chosen as promising DNA barcodes in other plants [26, 39, 63-65]; and petA-psb], rpl32-trnL, and rps15-ycf1 regions have been widely used for phylogenetic analyses [66-70]. In a future study, we will test whether or not these sequences can serve as reliable DNA barcodes for species identification within Peucedanum genus.

\section{Conclusion}

This study is the first attempt to comprehensively investigate the plastome features and infer phylogeny by using plastome data for Peucedanum genus. Comparative analyses found that plastomes of Peucedanum are conserved in terms of genome structure, codon bias, RNA editing sites, and SSRs, but varied in genome size, gene content and arrangement, and border of SC/IR. The plastid phylogenomic analyses prove that plastome data are efficient and powerful for improving the supports and resolutions of Peucedanum phylogeny and robustly support that 


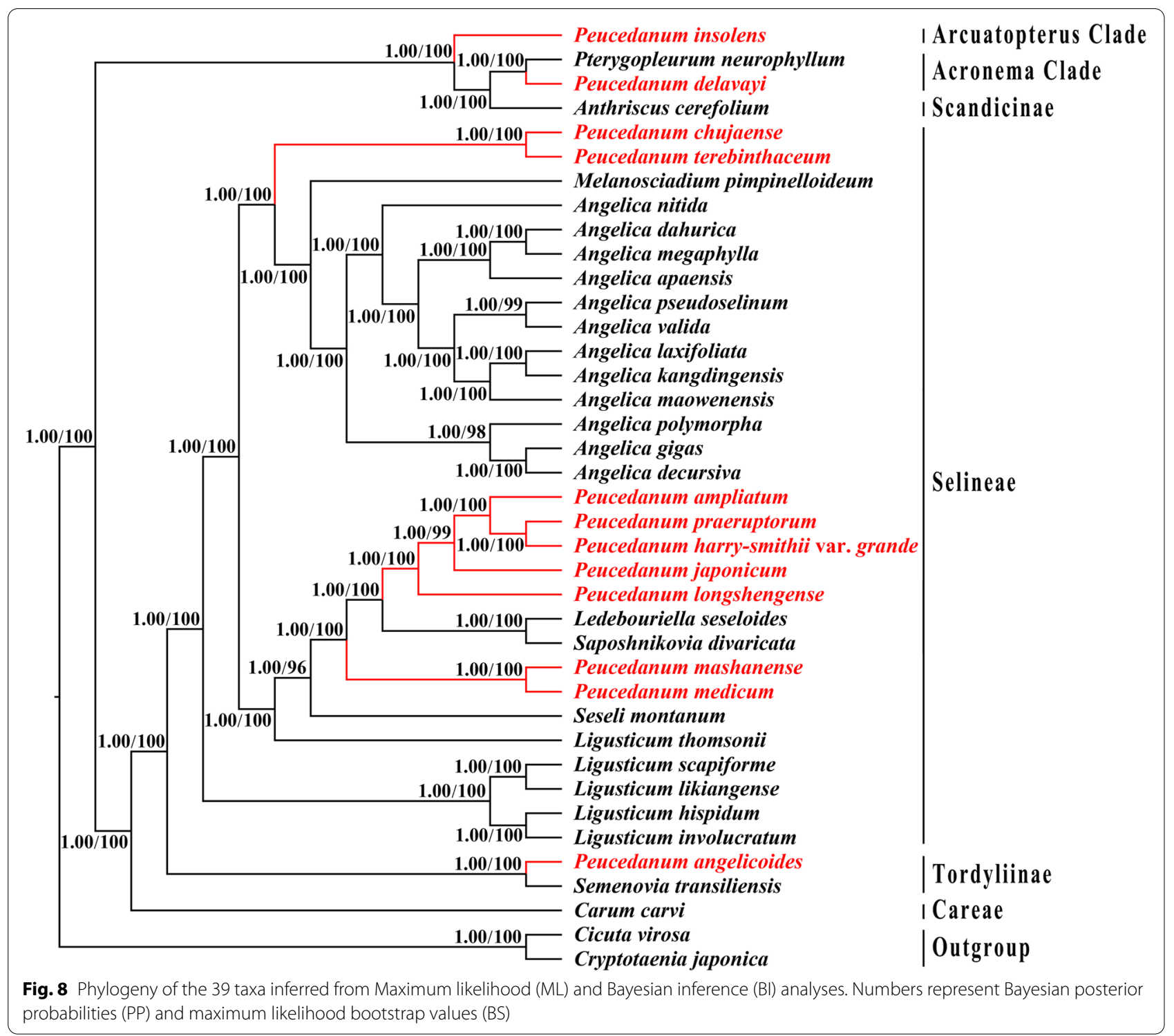

Peucedanum is not a monophyletic group. In addition, fifteen mutation hotspot regions are identified across the plastomes that can serve as potential DNA barcodes for species identification in Peucedanum. Overall, our study lays the foundations for the future phylogeny and taxonomy of Peucedanum.

\section{Methods}

Plant material, DNA extraction, plastome sequencing and assembly

The fresh young leaves of seven Peucedanum taxa were collected from the wild and the greenhouse in College of Life Sciences, Sichuan University, and then dried with silica gel. The formal identifications of all samples were undertaken by Professor Xingjin He (Sichuan University). The voucher specimens were deposited at the herbarium of Sichuan University (Chengdu, China) under deposition numbers of LCK2020001- LCK2020004, LZL2020085, JQP19082303, and JQP19082505 (Table S6). Total DNA was extracted from $\sim 20 \mathrm{mg}$ silicagel-dried leaves with the CTAB method [71]. Genomic DNA then was fragmented into $400 \mathrm{bp}$ to construct the pair-end library, following the manufacturer's protocol (Illumina, San Diego, CA, USA). The libraries were sequenced on the Illumina NovaSeq platform at Personalbio (Shanghai, China). Raw data were filtered using fastP v0.15.0 (-n 10 and $-\mathrm{q} 15$ ) to obtain high quality reads [72]. Then high-quality reads were used to assemble the whole plastome with NOVOPlasty v2.6.2 [73], 
with the default parameters and $r b c \mathrm{~L}$ sequence from $P$. japonicum (JF943288) as seed.

\section{Genomic annotation and feature analyses}

The assembled plastomes were annotated using web server CPGAVAS2 (http://www.herbalgenomics. org/cpgavas2) [74]. The start and stop codons and intron positions were manually corrected according to plastomes of congeneric species in Geneious v9.0.2 [75]. The maps of annotated plastomes were drawn using the online program OrganellarGenomeDRAW (OGDRAW) [76].

Five whole plastomes of Peucedanum (P. chujaense, $P$. delavayi, $P$. insolens, $P$. praeruptorum, and $P$. terebinthaceum) were downloaded from NCBI. Together with newly sequenced plastomes, we investigated the codon usage of Peucedanum plastomes with the CodonW v1.4.2 program [77]. Then, we predicted the potential RNA editing sites of protein coding genes for the twelve Peucedanum plastomes by using the online program Predictive RNA Editor for Plants suite with a cutoff value of 0.8 [78]. Moreover, simple sequence repeats (SSRs) for each plastomes were detected with MISA (http://pgrc.ipk-gater sleben.de/misa/). The thresholds of repeat units were set as $10,5,4,3,3$, and 3, for mono-, di-, tri-, tetra-, penta-, and hexanucleotides, respectively.

\section{Genomic comparison}

We compared the boundaries of the LSC, SSC and IR regions among the twelve Peucedanum plastomes in Geneious v9.0.2 [75]. Then, the DNA rearrangements among Peucedanum plastomes were detected by using Mauve Alignment [79] implemented in Geneious v9.0.2 [75]. Furthermore, sequence divergence of Peucedanum plastomes was investigated using the mVISTA tool [80], with $P$. ampliatum set as the reference.

\section{Identification of divergence hotspots}

In order to identify mutation hotspot regions, the protein coding genes, non-coding regions and intron regions of the twelve Peucedanum plastomes were extracted in Geneious v9.0.2 [75] and aligned with MAFFT v7.221 [81]. Then, alignments with more than $200 \mathrm{bp}$ in length were used to evaluate nucleotide diversity (Pi) using DnaSP v5.0 [82]. The thresholds of Pi for protein coding gene and non-coding region were set as 0.01200 and 0.03100 , respectively.

\section{Phylogenetic analyses}

To infer the phylogenetic relationships among Peucedanum species, we reconstructed phylogenetic trees using 39 plastomes (Table S6, Table S7). Cicuta virosa L. and
Cryptotaenia japonica Hassk. were chosen as outgroup to root the phylogenetic tree, according to the results of Wen et al. [37]. Sequence alignment was performed with the software MAFFT v7.221 [81], and adjusted and corrected manually when necessary. The unambiguous matrix was subjected to Maximum-Likelihood analyses (ML) and Bayesian Inference (BI). The ML phylogenetic tree was reconstructed in the program RAxML v8.2.8 [83] with 1000 replicates and GTRGAMMA model as the RAxML manual suggested. The BI analysis was performed by using MrBayes v3.2.7 [84] with the best-fit substitution model $(\mathrm{TVM}+\mathrm{I}+\mathrm{G})$ determined by Modeltest v3.7 [85]. Two independent Markov chains were run for 1,000,000 generations, sampling every 100 generations. The first $25 \%$ of trees were discarded as burn-in and the remainder were used to generate the consensus tree. Results of phylogenetic analyses were visualized and edited in FigTree v1.4.2 [86].

\section{Abbreviations}

BI: Bayesian inference; bp: Base pair; BS: Bootstrap value; CTAB: Cetyl trimethylammonium bromide; IR: Inverted repeat; ITS: Internal transcribed spacer; LSC: Large single copy; ML: Maximum Likelihood; Pi: Nucleotide diversity; PP: Posterior probability; rRNA: Ribosomal RNA; RSCU: Relative synonymous codon usage; SSC: Small single copy; SSR: Simple sequence repeat; tRNA: Transfer RNA.

\section{Supplementary Information}

The online version contains supplementary material available at https://doi. org/10.1186/s12870-022-03488-x.

Additional file 1: Fig. S1. Analyses of RNA editing sites in twelve Peucedanum plastomes: (A) numbers of RNA editing sites distributed in different codon positions; (B) numbers of RNA editing sites presented in genes.

Additional file 2: Table S1. Summary of Illumina sequencing of Peucedanum.

Additional file 3: Table S2. List of unique genes identified in plastomes of Peucedanum.

Additional file 4: Table S3. Codon usage and relative synonymous codon usage (RSCU) values of protein-coding genes of the twelve Peucedanum plastomes.

Additional file 5: Table S4. RNA editing sites detected in the twelve plastome of Peucedanum.

Additional file 6: Table S5. Numbers of SSR motifs identified in the twelve Peucedanum plastomes.

Additional file 7: Table S6. Taxa newly sequenced in the present study with source, voucher and GenBank accession numbers.

Additional file 8: Table S7. Plastomes included in phylogenetic analyses with GenBank accession.

\section{Acknowledgements}

We are grateful to Zhenlong Liang for his help in collecting samples and to Ziyoviddin Yusupov for his assistant in revising the English.

\section{Authors' contributions}

S-DZ and X-JH designed the research. C-KL, J-QL, and Q-PJ collected and analyzed the data; C-KL, S-DZ and X-JH prepared the manuscript. All authors read and approved the final manuscript. 


\section{Funding}

This work was supported by the National Natural Science Foundation of China (Grant No. 32170209, 32070221, 31872647), National Herbarium of China, National Herbarium resources teaching specimen database (Grant No. 2020BBFK01). The funders were not involved in the design of the research, collection, analysis and interpretation of data, and manuscript preparation.

\section{Availability of data and materials}

The seven newly sequenced plastomes have been submitted into NCBI with accession numbers: OK336473-OK336479.

\section{Declarations}

\section{Ethics approval and consent to participate}

Collection of all samples completely complies with national and local legislation permission. Plant samples used in the study were not included in the list of national key protected plants and not collected from national park or natural reserve. According to national and local legislation, no specific permission was required for collecting these plants.

\section{Consent for publication}

Not applicable.

\section{Competing interests}

The authors declare that they have no competing interests.

Received: 9 October 2021 Accepted: 2 February 2022

Published online: 07 March 2022

\section{References}

1. Sheh ML. Peucedanum. In: Shan RH, Sheh ML, editors. Flora Reipublicae Popularis Sinica. Beijing: Science Press; 1992. p. 123-75.

2. Spalik K, Reduron JP, Downie SR. The phylogenetic position of Peucedanum sensu lato and allied genera and their placement in tribe Selineae (Apiaceae, subfamily Apioideae). PI Syst Evol. 2004;243(3):189-210.

3. Sheh ML, Watson MF. Peucedanum Linnaeus. In: Wu ZY, Raven PH, Hong DY, editors. Flora of China. Beijing: Science Press \& St. Louis: Missouri Botanic Garden Press; 2005. p. 182-92.

4. Drude CGO. Umbelliferae. In: Engler A, Prantl K, editors. Die naturlichen Pflanzenfamilien. Leipzig: Wilhelm Engelmann; 1897-1898. p. 63-250.

5. Pimenov MG, Leonov MV. The genera of Umbelliferae. Kew: Royal Botanical Gardens; 1993

6. Wu ZY, Lu AM, Tang YC, Chen ZD, Li DZ. The families and genera of Angiosperms in China: a comprehensive analysis. Beijing: Science Press; 2003.

7. Zhang X. Studies on geographic distribution of Peucedanum L. in southwest of China. Chin Agric Sci Bull. 2011;27(12):177-80.

8. Downie SR, Spalik K, Katz-Downie DS, Reduron JP. Major clades within Apiaceae subfamily Apioideae as inferred by phylogenetic analysis of nrDNA ITS sequences. Plant Divers Evol. 2010;128(1):111-36.

9. Shneyer VS, Kutyavina NG, Pimenov MG. Systematic relationships within and between Peucedanum and Angelica (Umbelliferae-Peucedaneae) inferred from immunological studies of seed proteins. Plant Syst Evol. 2003:236(3):175-94.

10. Reduron JP, Charpin A, Pimenov MG. Contribution a' la nomenclature ge'ne'rique des Apiaceae (Ombellife`res). J Bot Soc Bot Fr. 1997;1:91-104.

11. Winter PJD, Magee AR, Phephu N, Tilney PM, Downie SR, van Wyk BE. A new generic classification for African peucedanoid species (Apiaceae). Taxon. 2008;57(2):347-64.

12. Downie SR, Watson MF, Spalik K, Katz-Downie DS. Molecular systematics of Old World Apioideae (Apiaceae): relationships among some members of tribe Peucedaneae sensu lato, the placement of several islandendemic species, and resolution within the apioid superclade. Can J Bot. 2000;78(4):506-28.

13. Valiejo-Roman CM, Terentieva El, Samigullin TH, Pimenov MG, Ghahremani-Nejad F, Mozaffarian V. Molecular data (nrlTS-sequencing) reveal relationships among Iranian endemic taxa of the Umbelliferae. Feddes Repert. 2006;117(5-6):367-88.
14. Feng T, Downie SR, Yu Y, Zhang XM, Chen WW, He XJ, et al. Molecular systematics of Angelica and allied genera (Apiaceae) from the Hengduan Mountains of China based on nrDNA ITS sequences: phylogenetic affinities and biogeographic implications. J Plant Res. 2009;122(4):403-14.

15. Zhou J, Gong X, Downie SR, Peng H. Towards a more robust molecular phylogeny of Chinese Apiaceae subfamily Apioideae: additional evidence from nrDNA ITS and cpDNA intron ( $r p / 16$ and rps16) sequences. Mol Phylogenet Evol. 2009;53(1):56-68.

16. Zhou J, Gao YZ, Wei J, Liu ZW, Downie SR. Molecular phylogenetics of Ligusticum (Apiaceae) based on nrDNA ITS sequences: rampant polyphyly, placement of the Chinese endemic species, and a much-reduced circumscription of the genus. Int J Plant Sci. 2020;181(3):306-23.

17. Kim K, Kim CS, Oh SH, Park CW. A new species of Peucedanum (Apiaceae) from Korea. Phytotaxa. 2019;393(1):75-83.

18. Sarkhail P. Traditional uses, phytochemistry and pharmacological properties of the genus Peucedanum: a review. J Ethnopharmacol. 2014:156:235-70.

19. Wicke S, Schneeweiss GM, Müller KF, Quandt D. The evolution of the plastid chromosome in land plants: gene content, gene order, gene function. Plant Mol Biol. 2011;76(3):273-97.

20. Shaw J, Shafer HL, Leonard OR, Kovach MJ, Schorr M, Morris AB. Chloroplast DNA sequence utility for the lowest phylogenetic and phylogeographic inferences in angiosperms, the tortoise and the hare IV. Am J Bot. 2014:101(11):1987-2004.

21. Tonti-Filippini J, Nevill PG, Dixon K, Small I. What can we do with 1000 plastid genomes? Plant J. 2017:90:808-e818.

22. Schneider JV, Paule J, Jungcurt T, Cardoso D, Amorim AM, Berberich $\mathrm{T}$, et al. Resolving recalcitrant clades in the pantropical Ochnaceae: insights from comparative phylogenomics of plastome and nuclear genomic data derived from targeted sequencing. Front Plant Sci. 2021;12:638650.

23. Ravi V, Khurana JP, Tyagi AK, Khurana P. An update on chloroplast genomes. Plant Syst Evol. 2008;271(1):101-22.

24. Guisinger MM, Kuehl JV, Boore $J \mathrm{~L}$, Jansen RK. Extreme reconfiguration of plastid genomes in the angiosperm family Geraniaceae: rearrangements, repeats, and codon usage. Mol Biol Evol. 2011;28(1):583-600.

25. Jansen RK, Cai Z, Raubeson LA, Daniell H, dePamphilis CW, Leebens-Mack J, et al. Analysis of 81 genes from 64 plastid genomes resolves relationships in angiosperms and identifies genome-scale evolutionary patterns. Proc Natl Acad Sci U S A. 2007;104(49):19369-74.

26. Wang M, Wang X, Sun J, Wang Y, Ge Y, Dong W, et al. Phylogenomic and evolutionary dynamics of inverted repeats across Angelica plastomes. BMC Plant Biol. 2021;21:26.

27. Nock CJ, Waters DLE, Edwards MA, Bowen SG, Rice N, Cordeiro GM, et al Chloroplast genome sequences from total DNA for plant identification. Plant Biotechnol J. 2011;9(3):328-33.

28. Ruhsam M, Rai HS, Mathews S, Ross TG, Graham SW, Raubeson LA, et al. Does complete plastid genome sequencing improve species discrimination and phylogenetic resolution in Araucaria? Mol Ecol Resour. 2015;15(5):1067-78.

29. Ji Y, Yang L, Chase MW, Liu C, Yang Z, Yang J, et al. Plastome phylogenomics, biogeography, and clade diversification of Paris (Melanthiaceae). BMC Plant Biol. 2019;19(1):543.

30. Li HT, Yi TS, Gao LM, Ma PF, Zhang T, Yang JB, et al. Origin of angiosperms and the puzzle of the Jurassic gap. Nat Plants. 2019;5(5):461-70.

31. Liu C, Yang J, Jin L, Wang S, Yang Z, Ji Y. Plastome phylogenomics of the East Asian endemic genus Dobinea. Plant Divers. 2021;43(1):35-42.

32. Parks M, Cronn R, Liston A. Increasing phylogenetic resolution at low taxonomic levels using massively parallel sequencing of chloroplast genomes. BMC Biol. 2009;7(1):84.

33. Lee HO, Joh HJ, Kim K, Lee SC, Kim NH, Park JY, et al. Dynamic chloroplast genome rearrangement and DNA barcoding for three Apiaceae species known as the medicinal herb "Bang-Poong". Int J Mol Sci. 2019;20(9):2196.

34. Li Y, Geng M, Xu Z, Wang Q, Li L, Xu M, et al. The complete plastome of Peucedanum praeruptorum (Apiaceae). Mitochondrial DNA B Resour. 2019:4(2):3612-3.

35. Gou W, Jia SB, Price M, Guo XL, Zhou SD, He XJ. Complete plastid genome sequencing of eight species from Hansenia, Haplosphaera and Sinodielsia (Apiaceae): comparative analyses and phylogenetic implications. Plants. 2020:9(11):1523. 
36. Kim K, Lim CE, Lee BY. The complete chloroplast genome sequence of Peucedanum chujaense (Apiaceae), an endemic species to Korea. Mitochondrial DNA B Resour. 2020;5(2):1937-8.

37. Wen J, Xie DF, Price M, Ren T, Deng Y, Gui L, et al. Backbone phylogeny and evolution of Apioideae (Apiaceae): new insights from phylogenomic analyses of plastome data. Mol Phylogenet Evol. 2021;161:107183.

38. Mwanzia VM, He DX, Gichira AW, Li Y, Ngarega BK, Karichu MJ, et al. The complete plastome sequences of five Aponogeton species (Aponogetonaceae): insights into the structural organization and mutational hotspots. Plant Divers. 2020;42(5):334-42.

39. Ren T, Li ZX, Xie DF, Gui LJ, Peng C, Wen J, et al. Plastomes of eight Ligusticum species: characterization, genome evolution, and phylogenetic relationships. BMC Plant Biol. 2020;20(1):519.

40. Mehmood F, Rahim A, Heidari P, Ahmed I, Peter P. Comparative plastome analysis of Blumea, with implications for genome evolution and phylogeny of Asteroideae. Eco Evolution. 2021;11(12):7810-26.

41. Nguyen PAT, Kim JS, Kim JH. The complete chloroplast genome of colchicine plants (Colchicum autumnale L. and Gloriosa superba L.) and its application for identifying the genus. Planta. 2015;242(1):223-37.

42. Shin DH, Lee JH, Kang SH, Ahn BO, Kim CK. The complete chloroplast genome of the hare's ear root, Bupleurum falcatum: its molecular features. Genes. 2016;7(5):20.

43. Sun $L$, Jiang $Z$, Wan $X$, Zou $X$, Yao $X$, Wang $Y$, et al. The complete chloroplast genome of Magnolia polytepala: comparative analyses offer implication for genetics and phylogeny of Yulania. Gene. 2020;736:144410.

44. Guo X, Liu C, Wang H, Zhang G, Yan H, Jin L, et al. The complete plastomes of two flowering epiparasites (Phacellaria glomerata and $P$. compressa): gene content, organization, and plastome degradation. Genomics. 2021;113(2):447-55.

45. Rokas A, Carroll SB. More genes or more taxa? The relative contribution of gene number and taxon number to phylogenetic accuracy. Mol Biol Evol. 2005;22:1337-44.

46. Philippe H, Brinkmann H, Lavrov DV, Littlewood DTJ, Manuel M, Wörheide $G$, et al. Resolving difficult phylogenetic questions: why more sequences are not enough. PLoS Biol. 2011;9:e1000602.

47. Huang Y, Li X, Yang Z, Yang C, Yang J, Ji Y. Analysis of complete chloroplast genome sequences improves phylogenetic resolution in Paris (Melanthiaceae). Front Plant Sci. 2016;7:1797.

48. Zhou J, Wang WC, Gong X, Liu ZW. Leaf epidermal morphology in Peucedanum L. (Umbelliferae) from China. Acta Bot Gallica. 2014;161(1):21-31.

49. Wang MY, Liu M, Cheng XY, Wang YT. The phylogenetic significance of fruit structures in Chinese Peucedanum of Apiaceae. Acta Pratac Sin. 2015;24(6):168-76.

50. Ostroumova TA. Fruit micromorphology in the Umbelliferae of the Russian Far East. Bot Pac. 2018:7(1):41-9.

51. Ostroumova TA, Pimenov MG, Degtjareva GV, Samigullin TH. Taeniopetalum Vis. (Apiaceae), a neglected segregate of Peucedanum L., supported as a remarkable genus by morphological and molecular data. Skvortsovia. 2016;3:20-44

52. Pimenov MG, Ostroumova TA, Degtjareva GV, Samigullin TH. Sillaphyton, a new genus of the Umbelliferae, endemic to the Korean Peninsula. Bot Pac. 2016;5(2):31-41.

53. Li X, Yang Y, Henry RJ, Rossetto M, Wang Y, Chen S. Plant DNA barcoding: from gene to genome. Biol Rev. 2015;90(1):157-66.

54. Hajibabaei M, Janzen DH, Burns JM, Hallwachs W, Hebert PDN. DNA barcodes distinguish species of tropical Lepidoptera. Proc Natl Acad Sci U S A. 2006;103(4):968-71

55. Costa FO, DeWaard JR, Boutillier J, Ratnasingham S, Dooh RT, Hajibabaei M, et al. Biological identifications through DNA barcodes: the case of the Crustacea. Can J Fish Aquat Sci. 2007;64(2):272-95.

56. Smith MA, Poyarkov NA, Hebert PDN. DNA barcoding: CO1 DNA barcoding amphibians: take the chance, meet the challenge. Mol Ecol Resour. 2008;8(2):235-46.

57. Kim DW, Yoo WG, Park HC, Yoo HS, Kang DW, Jin SD, et al. DNA barcoding of fish, insects, and shellfish in Korea. Genomics Inform. 2012:10(3):206-11.

58. Hollingsworth PM, Forrest LL, Spouge JL, Hajibabaei M, Ratnasingham $\mathrm{S}$, van der Bank $\mathrm{M}$, et al. A DNA barcode for land plants. Proc Natl Acad Sci U S A. 2009:106(31):12794-7.
59. Hollingsworth PM. Refining the DNA barcode for land plants. Proc Natl Acad Sci U S A. 2011;108(49):19451-2.

60. Hollingsworth PM, Graham SW, Little DP. Choosing and using a plant DNA barcode. PLoS One. 2011;6(5):e19254.

61. Coissac E, Hollingsworth PM, Lavergne S, Taberlet P. From barcodes to genomes: extending the concept of DNA barcoding. Mol Ecol. 2016;25:1423-8.

62. Hollingsworth PM, Li DZ, van der Bank M, Twyford AD. Telling plant species apart with DNA: from barcodes to genomes. Philos Trans R Soc B. 2016;371(1702):20150338.

63. Liu C, Yang Z, Yang L, Yang J, Ji Y. The complete plastome of Panax stipuleanatus: Comparative and phylogenetic analyses of the genus Panax (Araliaceae). Plant Divers. 2018;40(6):265-76.

64. Xie DF, Yu HX, Price M, Xie C, Deng YQ, Chen JP, et al. Phylogeny of Chinese Allium species in section Daghestanica and adaptive evolution of Allium (Amaryllidaceae, Allioideae) species revealed by the chloroplast complete genome. Front Plant Sci. 2019;10:460.

65. Dong W, Liu Y, Xu C, Gao Y, Yuan Q, Suo Z, et al. Chloroplast phylogenomic insights into the evolution of Distylium (Hamamelidaceae). BMC Genomics. 2021;22(1):293.

66. Ngamriabsakul C, Techaprasan J. The phylogeny of Thai Boesenbergia (Zingiberaceae) based on petA-psbJ spacer (chloroplast DNA). J Sci Technol. 2006;28:49-57.

67. Jaramillo MA, Callejas R, Davidson C, Smith JF, Stevens AC, Tepe EJ. A phylogeny of the tropical genus Piper using ITS and the chloroplast intron psbJ-petA. Syst Bot. 2008;33(4):647-60.

68. Falchi A, Paolini J, Desjobert JM, Melis A, Costa J, Varesi L. Phylogeography of Cistus creticus L. on Corsica and Sardinia islands inferred by the trnL-F and rp/32-trnL sequences of cpDNA. Mol Phylogenet Evol. 2009;52(2):538-43.

69. Yang JB, Yang HQ, Li DZ, Wong KM, Yang YM. Phylogeny of Bambusa and its allies (Poaceae: Bambusoideae) inferred from nuclear GBSSI gene and plastid psbA-trnH, rp/32-trnL and rps 16 intron DNA sequences. Taxon. 2010;59(4):1102-10.

70. Chen YP, Drew BT, Li B, Soltis DE, Soltis PS, Xiang CL. Resolving the phylogenetic position of Ombrocharis (Lamiaceae), with reference to the molecular phylogeny of tribe Elsholtzieae. Taxon. 2016;65(1):123-36.

71. Doyle JJ, Doyle JL. Arapid DNA isolation procedure for small quantities of fresh leaf tissue. Phytochem Bull. 1987;19:11-5.

72. Chen S, Zhou Y, Chen Y, Gu J. Fastp: an ultra-fast all-in-one FASTQ preprocessor. Bioinformatics. 2018;34(17):i884-90.

73. Dierckxsens N, Mardulyn P, Smits G. NOVOPlasty: de novo assembly of organelle genomes from whole genome data. Nucleic Acids Res. 2017:45(4):e18

74. Shi L, Chen H, Jiang M, Wang L, Wu X, Huang L, et al. CPGAVAS2, an integrated plastome sequence annotator and analyzer. Nucleic Acids Res. 2019;47(W1):W65-73.

75. Kearse M, Moir R, Wilson A, Stones-Havas S, Cheung M, Sturrock S, et al. Geneious basic: an integrated and extendable desktop software platform for the organization and analysis of sequence data. Bioinformatics. 2012;28:1647-9.

76. Lohse M, Drechsel O, Bock R. OrganellarGenomeDRAW (OGDRAW): a tool for the easy generation of high-quality custom graphical maps of plastid and mitochondrial genomes. Curr Genet. 2007;52:267-74.

77. Peden JF. Analysis of codon usage. PhD thesis. Nottingham: University of Nottingham; 1999.

78. Mower JP. The PREP suite: predictive RNA editors for plant mitochondrial genes, chloroplast genes, and user-defined alignments. Nucleic Acids Res. 2009;37:W253-9.

79. Darling ACE, Mau B, Blattner FR, Perna NT. Mauve: multiple alignment of conserved genomic sequence with rearrangements. Genome Res. 2004;14(7):1394-403.

80. Frazer KA, Pachter L, Poliakov A, Rubin EM, Dubchak I. VISTA: computational tools for comparative genomics. Nucleic Acids Res. 2004:32(suppl_2):W273-9.

81. Katoh K, Standley DM. MAFFT multiple sequence alignment software version 7: improvements in performance and usability. Mol Biol Evol. 2013;30(4):772-80

82. Librado P, Rozas J. DnaSP v5: a software for comprehensive analysis of DNA polymorphism data. Bioinformatics. 2009;25:1451-2. 
83. Stamatakis A. RAxML version 8: a tool for phylogenetic analysis and post-analysis of large phylogenies. Bioinformatics. 2014;30(9):1312-3.

84. Ronquist F, Teslenko M, van der Mark P, Ayres DL, Darling A, Höhna S, et al. MrBayes 3.2: efficient Bayesian phylogenetic inference and model choice across a large model space. Syst Biol. 2012;61(3):539-42.

85. Posada D, Crandall KA. Modeltest: testing the model of DNA substitution. Bioinformatics. 1998;14(9):817-8

86. Rambaut A, Drummond A. FigTree, version 1.4.2. 2015. http://tree.bio.ed ac.uk/software/figtree/. Accessed 4 Oct 2021.

\section{Publisher's Note}

Springer Nature remains neutral with regard to jurisdictional claims in published maps and institutional affiliations.

- fast, convenient online submission

- thorough peer review by experienced researchers in your field

- rapid publication on acceptance

- support for research data, including large and complex data types

- gold Open Access which fosters wider collaboration and increased citations

- maximum visibility for your research: over $100 \mathrm{M}$ website views per year

At BMC, research is always in progress.

Learn more biomedcentral.com/submissions 